\title{
Comparing the Performance of Unconventional Median U-turn Intersections and Signalized Intersections: A Simulation Study
}

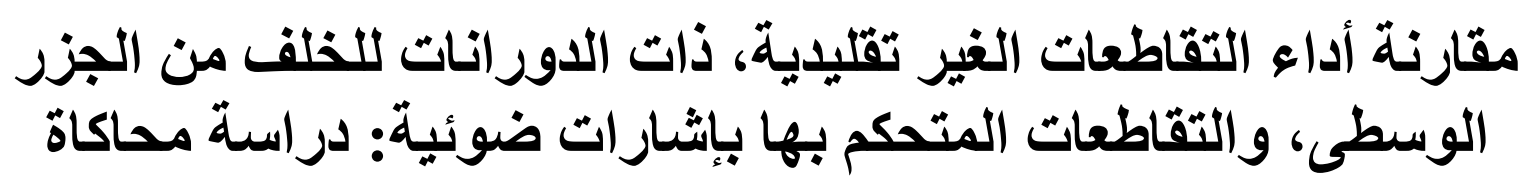

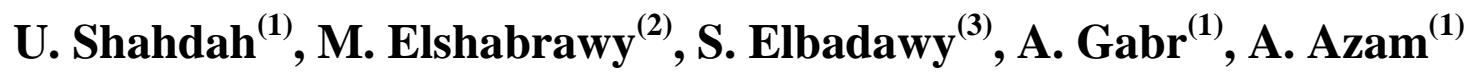

${ }^{(1)}$ Assistant Professor, Public Works Engineering Department, Faculty of Engineering, Mansoura University ${ }^{(2)}$ Professor emeritus, Public Works Engineering Department, Faculty of Engineering, Mansoura University

${ }^{(3)}$ Associate Professor, Public Works Engineering Department, Faculty of Engineering, Mansoura University Mansoura, Egypt 35516

Tel: +20-128-798-1901, Fax: +20-50-224-4690

Email: usama.shahdah@mans.edu.eg

\begin{abstract}
الملخص:

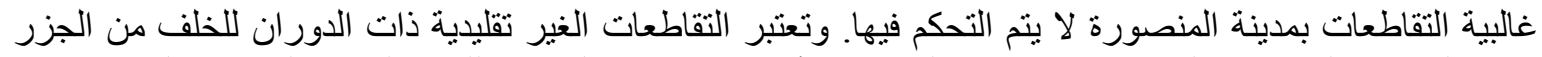

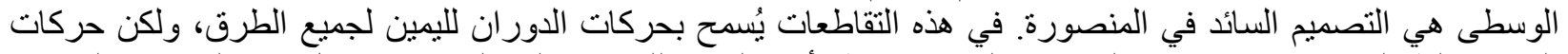

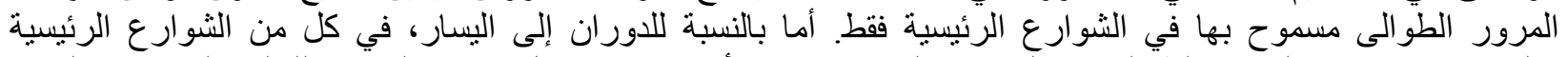

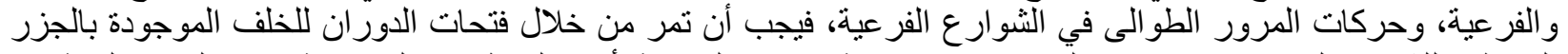

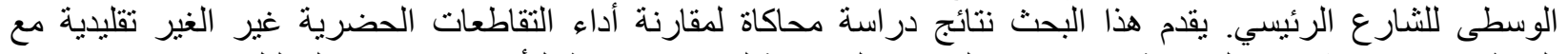

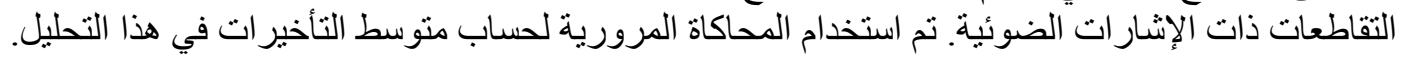

\section{ABSTRACT}

The Majority of intersections in Mansoura City are not controlled. The unconventional median U-turn (MUT) intersection design is the dominant design in Mansoura. In MUTs, right-turn movements are allowed for all approaches, but through movements are allowed only for the main street traffic. For left-turn in both the major and the minor streets and for through movements for the minor street traffic, vehicles must go through the U-turns in the median to complete their movement. For example, through movements on the minor street have to turn-right first into the main street then make a U-turn into the main street before making a right-turn into the minor street to continue to their destination. This paper presents the results of a simulation study for comparing the performance of the urban non-stranded 4-leg intersections with the signalized intersections. The VISSIM microscopic traffic simulation model was used in this analysis. The average delay per vehicle was used as the main measure of performance of the different intersections design with different traffic volumes.

Keywords: Median U-turn intersections, Signalized intersections, Average delay, Queue length, Traffic microsimulation, VISSIM. 


\section{INTRODUCTION}

The application of the unconventional median U-turns (MUTs) is the most common design at intersections in Mansoura City (i.e., the capital of the Dakahliya Governorate in Egypt). There are only two pre-timed signalized intersections, in which police officers can also manually control them.

A typical unconventional MUT traffic movements for both the major and minor streets is shown in Figure 1. As shown in Figure 1, right-turn movements are allowed for all approaches, but through movements are allowed only for the main street traffic. Left-turns are prohibited at the intersection for both the major and the minor streets. The through movements for the minor street traffic are also prohibited. For the prohibited movements, vehicles are moved to the median crossover located in the major streets beyond the intersection. The crossover can be located also in the minor street and can be either signalized or not (Autey et. al, 2010), but in Mansoura they are un-signalized and located in the major streets. In case of signalization, through movements for both streets are allowed. However, the un-signalized MUTs reported lower delays compared to signalize ones (Autey et. al, 2010).

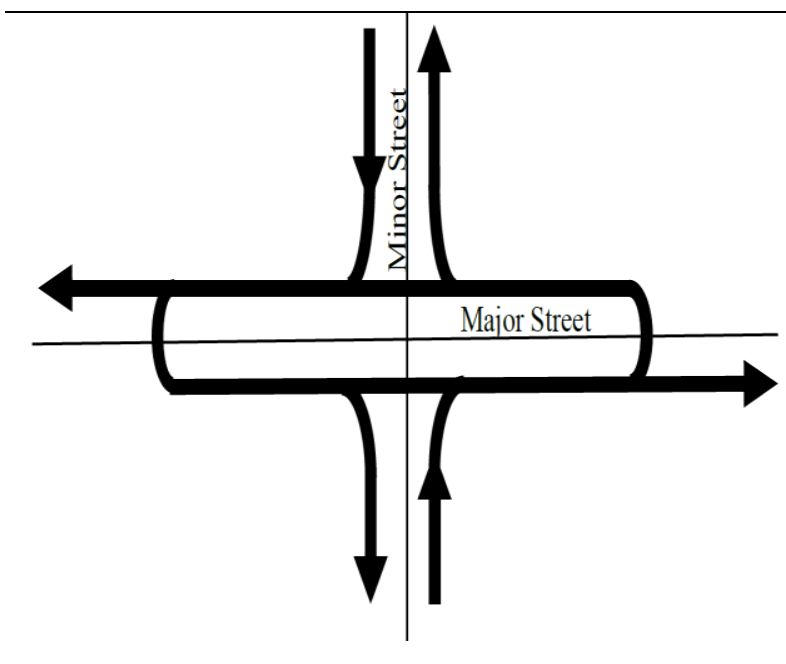

(a)

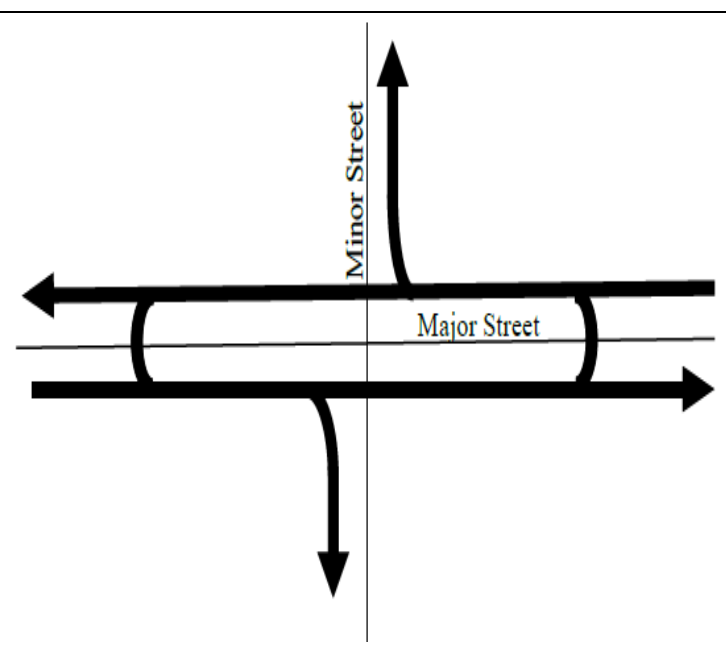

(b)

\section{Figure 1: Unconventional MUT Intersection Movements: (a) Minor Street Movements, (b) Major Street Movements (FHWA, 2004)}

While MUTs perform well for low traffic demands, they perform very poor for high traffic demands and near capacity traffic volumes, such as those in Cairo, Egypt (El Saway and Elsayed, 2011). Although the MUT design in case of heavy left-turn movements is not recommended (e.g., El Esawey and Elsayed, 2011; Autey et. al, 2010; etc.), MUTs are still used in
Mansoura regardless of the traffic demand and left-turn volumes at intersections.

The primary objective of this research is to assess the performance of the unconventional MUT design at 4-leg intersections, in Mansoura, and compare its performance against signalized intersections. The average vehicle delay was used as the main measure of effectiveness in this 
comparison. The microscopic traffic simulation model, VISSIM 5.40 (PTV, 2012), was used to model and analyze the unconventional MUT and the signalized intersections.

\section{MICROSIMULATION OF TRAFFIC:}

Figure 2 shows the geometric design for both the unconventional MUT and the signalized intersection. As shown in Figure 2, the major street consists of two lanes in both the East and the West approaches, while the minor street consists of only one lane in both the North and the South approaches. In this analysis only L (i.e., the location of the median U-turn in the major street from the intersection center) of $100 \mathrm{~m}$ and $\mathrm{W}$ (i.e., the median width) of $10 \mathrm{~m}$ were used. Other distances and median widths can be used, but in this analysis only $\mathrm{L}=100 \mathrm{~m}$ and $\mathrm{W}=10 \mathrm{~m}$ were tested. It is worth noting that the length " $L$ " will have an effect on the performance of the MUT, as it represent the length of the weaving segment. The effect of the weaving segment is behind the scope of this paper.

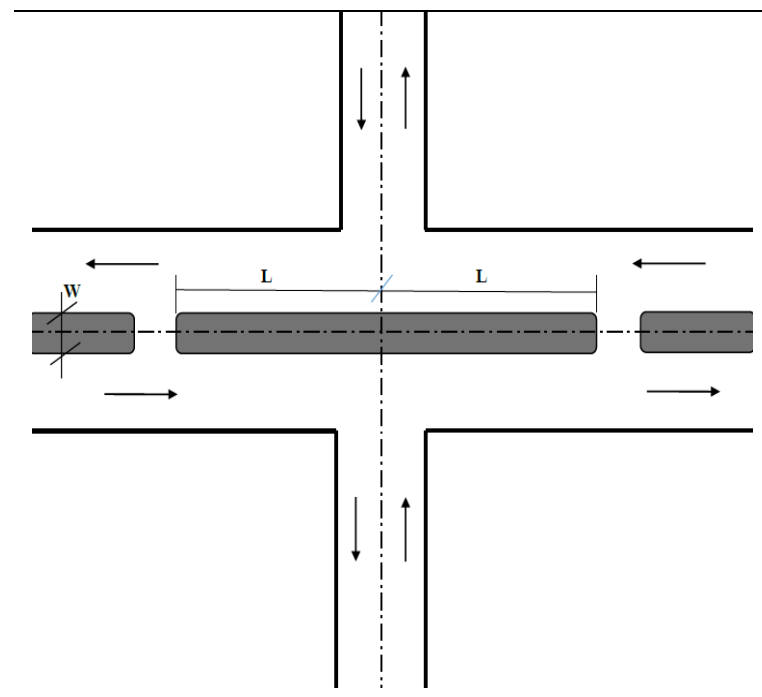

(a)

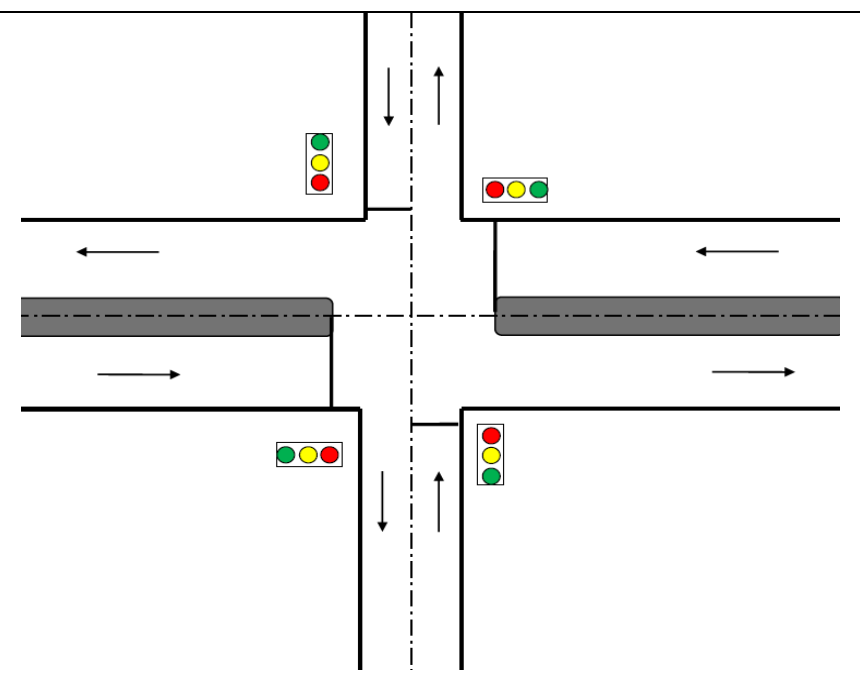

(b)

Figure 2: Geometric of The Intersections (a) The Unconventional MUT and (b) The Signalized Intersection

Seven different levels of traffic demand in the major street were used in this analysis: 500, 750, 1000, 1250, 1500, 1750 and 2000 vehicles per hour (vph). For each traffic demand level in the major street, there were four different traffic demand levels in the minor street: 250, 500, 750 and $1000 \mathrm{vph}$. Each traffic scenario used in this analysis was examined for three different left-turn traffic volumes: $30 \%, 20 \%$ and
$10 \%$ of the total approach traffic volume, as shown in Table 1.

Table 1: Left-Turn, Through and Right-Turn percentages from the Total approach volume

\begin{tabular}{|c|c|c|}
\hline \% Left-Turn & \% Through & \% Right-Turn \\
\hline 30 & 60 & 10 \\
\hline 20 & 70 & 10 \\
\hline 10 & 80 & 10 \\
\hline
\end{tabular}


Eighty-four simulation scenarios were considered in this analysis (i.e., (7 demand levels in the major street) $\mathrm{X}$ (4 demand levels in minor street) $\mathrm{X}$ (3 left-turn levels) $=84$ scenarios). The inputs into the simulation were the intersection approach volumes and turning movements (through, left-turn and right-turn), as reported in Table 1. For each simulation scenario, 12 simulation runs with 12 random seeds were used to capture the randomness in traffic with 10-minutes warming-up period. Although only one hour analysis period was used in this simulation study, a 2-hour simulation time was used to ensure that all vehicles have entered the simulation network.

The VISSIM parameters used in this analysis are summarized in Table 2. These parameters were selected to reflect more realistic driving behaviour in Mansoura. For example, from our observations on driving behaviours in Mansoura, vehicles can overtake other vehicles on the same lane on either the right or the left. This behaviour can be modelled in VISSIM by allowing this kind of behaviour by adjusting the lateral movement parameters to allow overtaking on same lane and on both the right and the left.

The VISSIM model was extensively used in the literature to model drivers' behaviours for different transportation studies (e.g., Shahdah et.al, 2014; El Esawey and Elsayed, 2011; Autey et. al, 2010; Duong et. al, 2010; Cunto and Saccomanno, 2008; Archer, 2005; Gettman and Head, 2003; etc.). Moreover, the VISSIM model was used in this analysis due to its flexibility to model the unconventional MUT, as the model is a link-connector model.
Table 2: Vissim Parameters

\begin{tabular}{|c|c|}
\hline $\begin{array}{l}\text { Behavioral } \\
\text { Parameter }\end{array}$ & Value \\
\hline Driving Behavior & Urban (Motorized) \\
\hline \multirow{5}{*}{ Car-Following } & Wiedemann 74 with \\
\hline & $\begin{array}{l}\text { Average standstill distance } \\
(\mathrm{ax})=1.00 \mathrm{~m}\end{array}$ \\
\hline & $\begin{array}{l}\text { Additive part of safety } \\
\text { distance }(\text { bx_add })=2.00\end{array}$ \\
\hline & $\begin{array}{l}\text { Multiplicity part of safety } \\
\text { distance (bx_mult) }=3.00\end{array}$ \\
\hline & Smooth close-up \\
\hline \multirow{5}{*}{ Lane Change } & Advanced Merging \\
\hline & $\begin{array}{l}\text { Overtake Reduced Speed } \\
\text { Areas }\end{array}$ \\
\hline & Cooperative lane change \\
\hline & $\begin{array}{l}\text { Maximum Deceleration for } \\
\text { cooperative lance change = - } \\
6.00 \mathrm{~m} / \mathrm{S}^{2}\end{array}$ \\
\hline & Free Lane Selection \\
\hline \multirow{4}{*}{$\begin{array}{l}\text { Lateral } \\
\text { Parameters }\end{array}$} & $\begin{array}{l}\text { Keep lateral Distance to } \\
\text { vehicles on next lane(s) }\end{array}$ \\
\hline & $\begin{array}{l}\text { Consider next turning } \\
\text { decision }\end{array}$ \\
\hline & $\begin{array}{l}\text { Desired Position at Free } \\
\text { Flow = Any }\end{array}$ \\
\hline & $\begin{array}{l}\text { Overtake on Same Lane: On } \\
\text { Right \& On Left }\end{array}$ \\
\hline
\end{tabular}

In this analysis, the signalized intersection was modeled as a pre-timed signal (i.e., fixed time) with 2 phases without exclusive phase for left-turn vehicles. The cycle times and cycle splits for both the major and minor streets were determined based on the major street traffic volume with the maximum traffic volume in the minor street (i.e., $1000 \mathrm{vph}$ ). The yellow and the all-red times were set to $4 \mathrm{sec}$. and 2 sec., respectively. The Synchro software version 8.0 (Trafficware, 2015) was used to determine the optimum cycle time and optimum splits. Table 3 summarize the cycle times and splits used in this paper. It is worth noting that Cycle times and splits for the rest of the 84 simulation scenarios (i.e., combinations) will yield different cycle 
times, but they were reduced in this study to only seven timing plans to reduce the analysis effort.

Furthermore, in this analysis the traffic composition was assumed to consist of only passenger cars (PCs) with no heavy vehicles or trucks. In addition, there is absolutely no pedestrians in the simulation network and vehicles parking is prohibited in all the simulated intersections' approaches.

Table 3: Cycle Times and Splits for Different Traffic Volumes

\begin{tabular}{|c|c|c|c|c|}
\hline $\begin{array}{c}\text { Major Street } \\
\text { Demand (vph) }\end{array}$ & $\begin{array}{c}\text { Minor Street } \\
\text { Demand (vph) }\end{array}$ & $\begin{array}{c}\text { Cycle Length } \\
\text { (Sec.) }\end{array}$ & $\begin{array}{c}\text { Major Street } \\
\text { Split }\end{array}$ & $\begin{array}{c}\text { Minor Street } \\
\text { Split }\end{array}$ \\
\hline 500 & 1000 & 70 & 50 & 20 \\
\hline 750 & 1000 & 80 & 50 & 30 \\
\hline 1000 & 1000 & 100 & 60 & 40 \\
\hline 1250 & 1000 & 140 & 80 & 60 \\
\hline 1500 & 1000 & 150 & 75 & 75 \\
\hline 1750 & 1000 & 150 & 75 & 75 \\
\hline 2000 & 1000 & 150 & 75 & 75 \\
\hline
\end{tabular}

\section{RESULTS:}

The simulated average delay per vehicle for the unconventional MUT at 30\%, $20 \%$ and $10 \%$ left-turn traffic volumes are shown in Figure 3. Figure 3 shows that the average delay per vehicle will increase by increasing the traffic demand in both the major and the minor streets. In addition, Figure 3 shows that the average delay per vehicle increases as the percentage of leftturn vehicles increases. For example, when both the major and the minor streets demand was $750 \mathrm{vph}$, the average delay decreased from $91.50 \mathrm{sec}$ at $30 \%$ left-turn volume to $57.50 \mathrm{sec}$ at $20 \%$ left-turn volume (i.e., with reduction in delay by $34 \mathrm{sec})$. When the leftturn volume was only $10 \%$, the delay value was only $25.00 \mathrm{sec}$, which shows a delay reduction by $66.50 \mathrm{sec}$ and 32.50 compared to the $30 \%$ and the $20 \%$ left-turn volumes, respectively.

Similarly, the simulated average delay per vehicle for the pre-timed signalized intersection at 30\%, 20\% and 10\% left-turn traffic volumes are shown in Figure 3 . Figure 3 show that by increasing the traffic volume in the major street, the delay will increase. In addition, Figure 3 shows that for different traffic volumes in the minor street and the same traffic volume in the major street, there is a slight change in the average delay compared to those at same traffic volumes at the unconventional MUT intersections. 


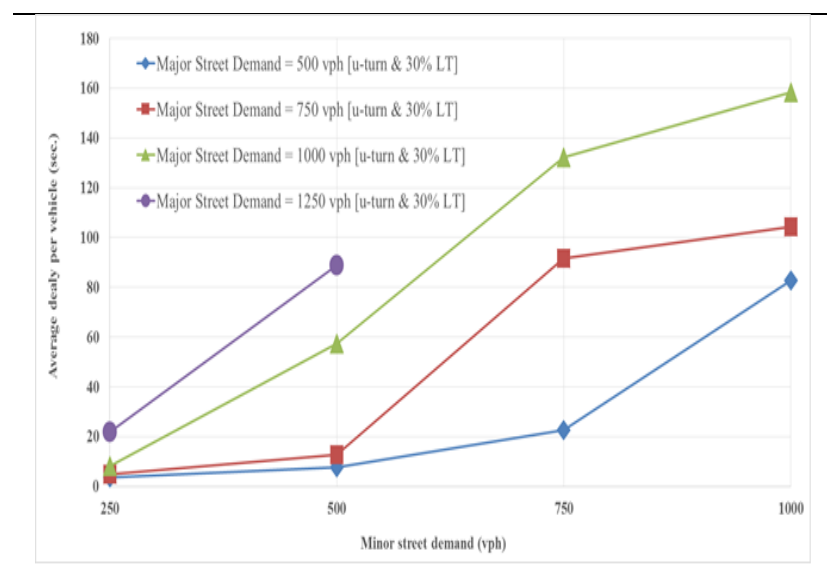

(a) Unconventional MUT \& 30\% LT

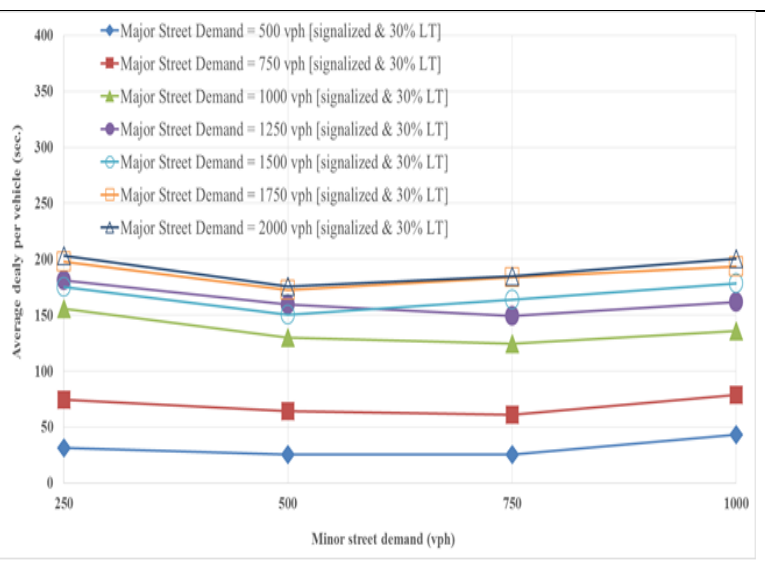

(d) Signalized Intersection \& $30 \%$ LT

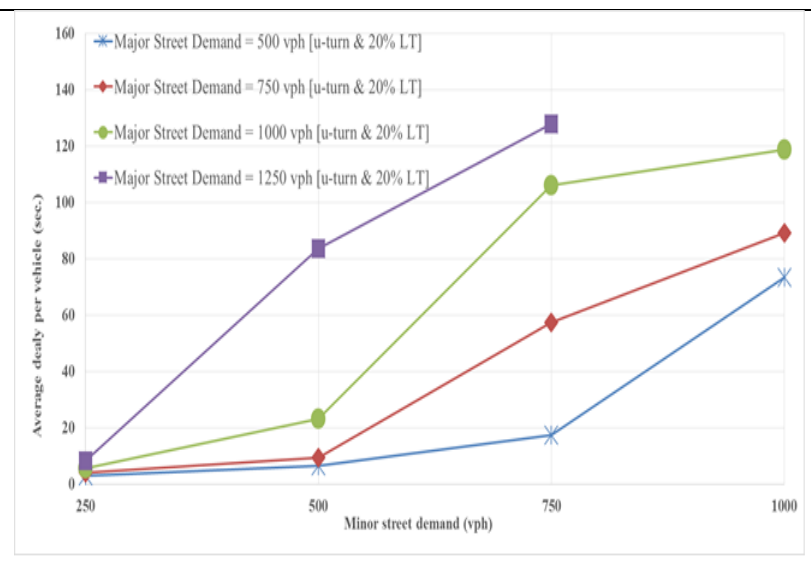

(b) Unconventional MUT \& 20\% LT

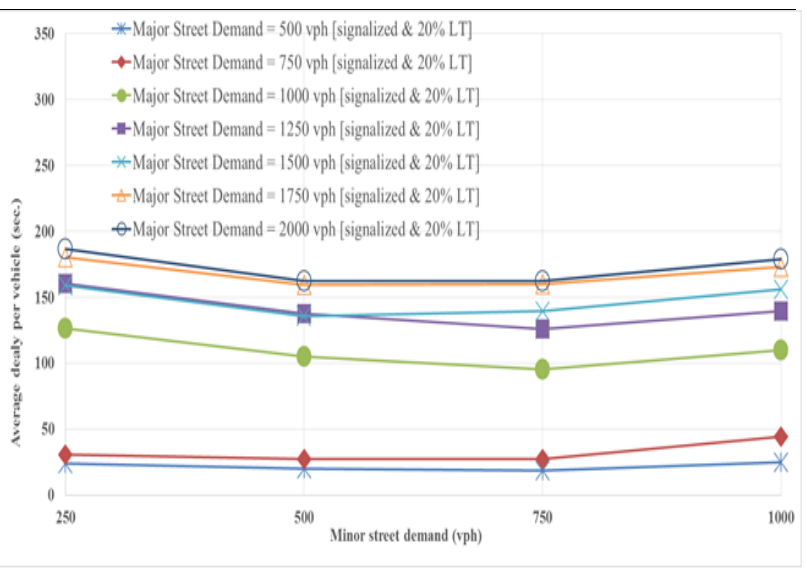

(e) Signalized Intersection \& 20\% LT

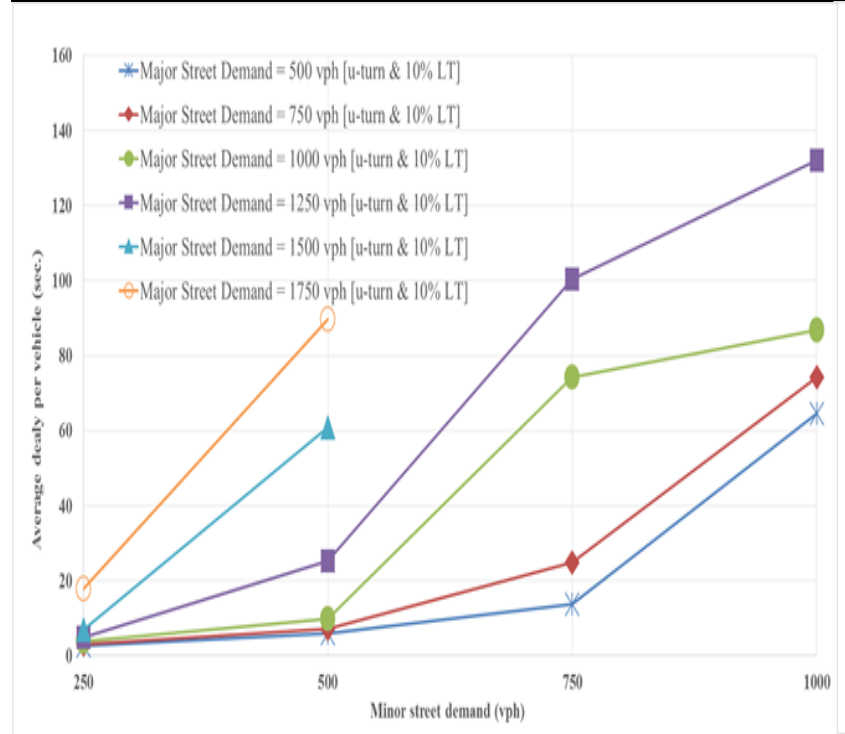

(c) Unconventional MUT \& $10 \%$ LT

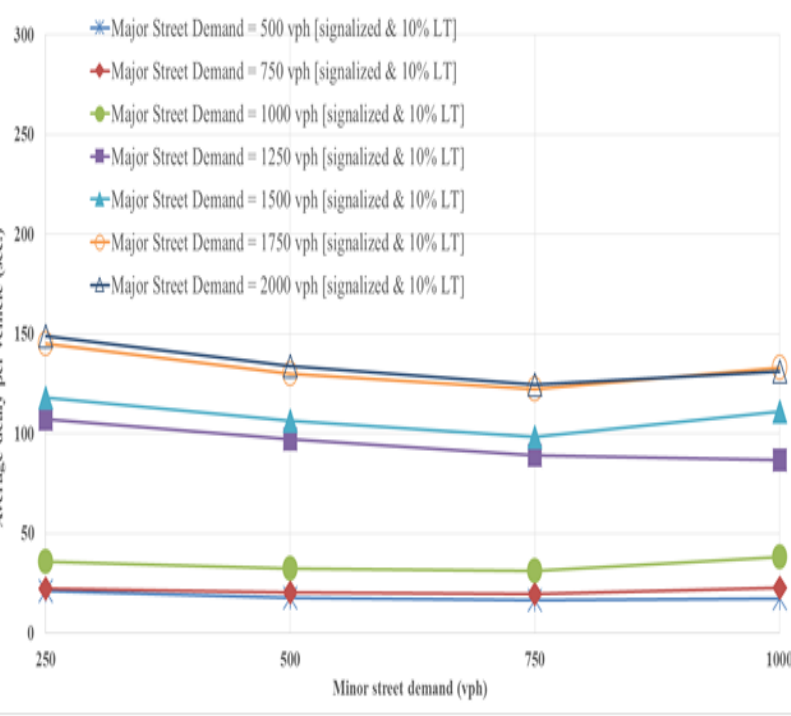

(f) Signalized Intersection \& 10\% LT

Figure 3: Average Delay per Vehicle at the Unconventional MUT and the Signalized Intersections with 30\%, $20 \%$ and $10 \%$ Left-Turn traffic Volumes 
Furthermore, Figure 3 shows that by increasing the total intersection traffic demand (i.e., sum of traffic demands from all approaches) at the unconventional MUT intersection, the vehicles will no longer able to complete their trip through the intersection. Those trips are not shown in Figure 3, as VISSIM estimated delay only for vehicles that completed their trips through the intersection. Vehicles that are queued at the intersection for an opportunity to complete their turn, VISSIM will report their delay as zero.

Figure 4 shows the relationship between the simulated traffic volume, for vehicles that successfully completed their trip through the intersection, and the total traffic demand at the intersection for both the unconventional MUT and the pre-timed signalized intersection. From Figure 4, it can be shown that for total intersection traffic demand $\geq 3500 \mathrm{vph}$, the number of vehicles that were able to make it through the intersection are smaller than the total intersection demand. Figure 4 shows that for many cases there are absolutely no vehicles were able to make it through the intersection in the case of the unconventional MUT intersection design, especially when the traffic demand $\geq 3500 \mathrm{vph}$. In the case of the signalized intersection design, vehicles will need an extra time to be able to complete their trip through the intersection.

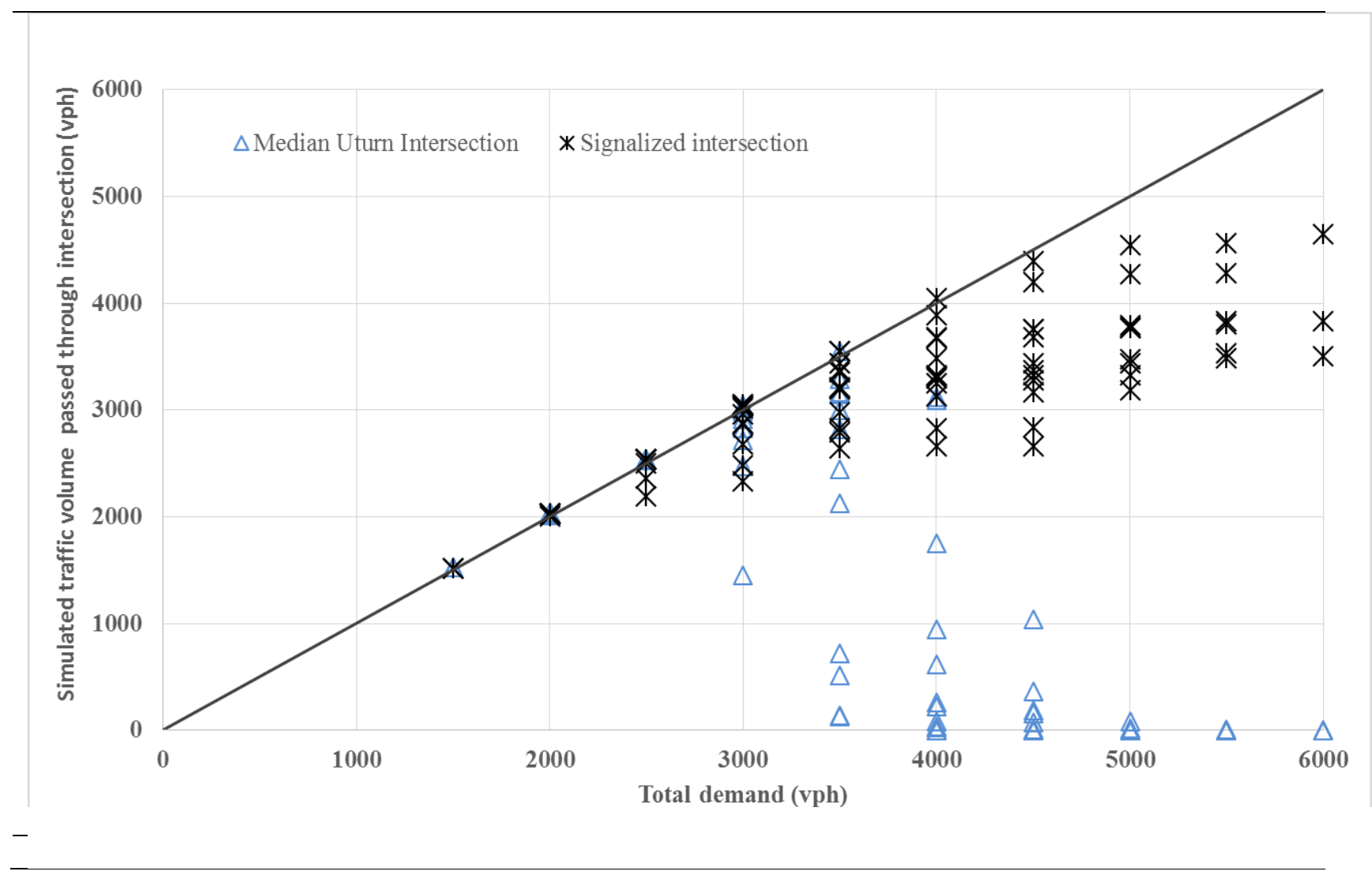


Figure 5 summarizes the comparison between the unconventional MUT intersection design and the signalized intersection design in terms of the average delay per vehicle. As shown in Figure 5, the average delays associate with the unconventional MUT design is much smaller than those associated with the signalized intersection. For low traffic demands (i.e., $\leq 2500 \mathrm{vph}$ ), the percentage of left-turn vehicles has almost no effect in the average delay values associated with the unconventional, but it has an effect in the case of the signalized intersection. As the intersection traffic demand increases (i.e., $\geq 2500 \mathrm{vph}$ ), the percentage of the left-turn vehicles will affect the delay values for both intersection design. For traffic volume $\geq 3500 \mathrm{vph}$, the unconventional MUT design will be critically affected by the percentage of left-turn vehicles. For heavy traffic demand, the comparison between the two intersection design is not possible, as the unconventional MUT design was not possible in VISSIM because the vehicles weren't able to complete their trips through the intersection.

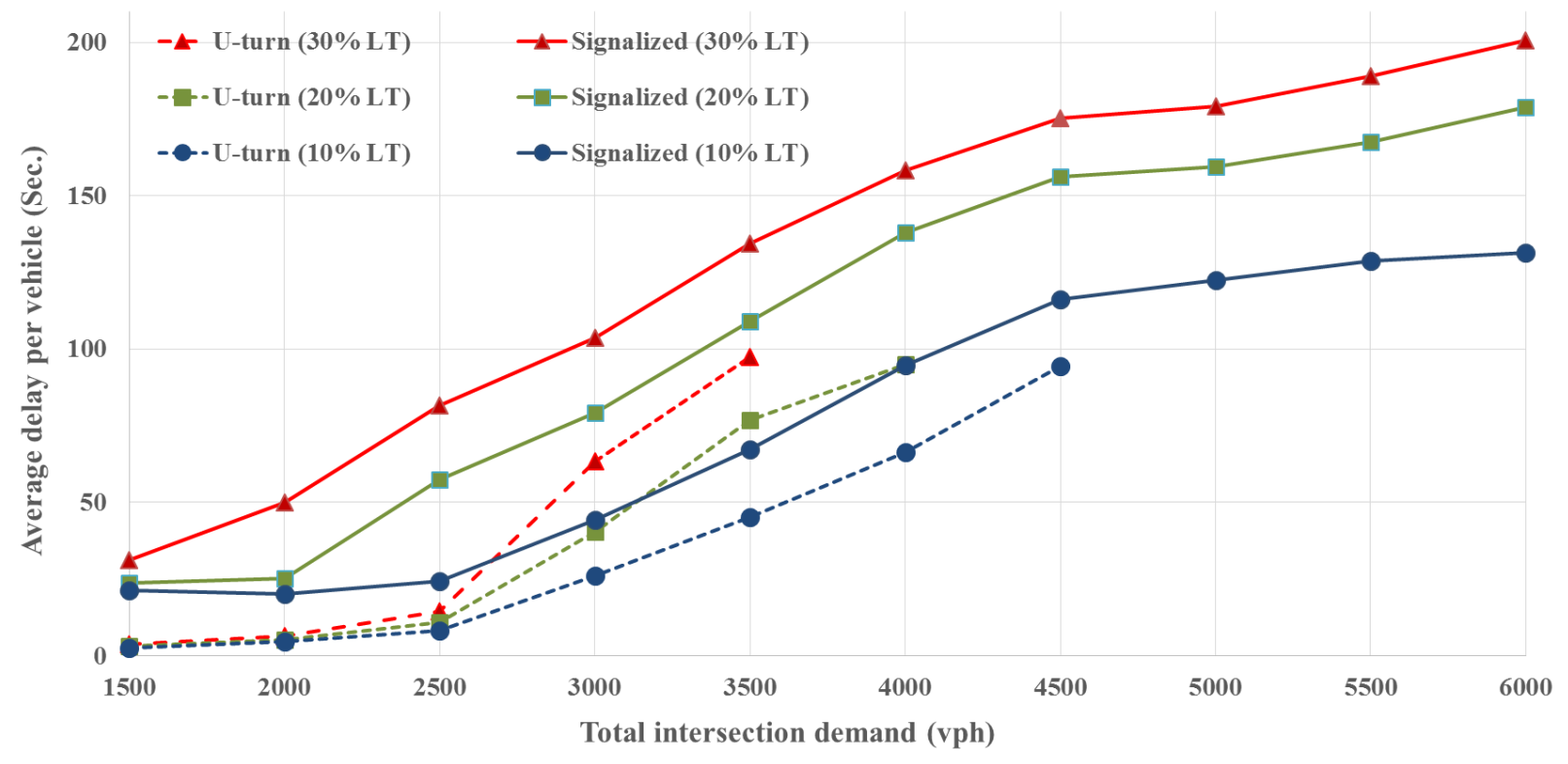

Figure 5: Comparing the Average Delay for the unconventional MUT and the signalized intersections.

\section{CONCLUSION}

The paper presents the results of a simulation study to evaluate the unconventional median U-turn intersection design at urban 4-leg intersection, with 2lanes in the major street and one lane in the minor street, and compare it against the pretimed signalized intersection design. In this analysis, the traffic composition was assumed to contain only passenger cars with no pedestrians. The median U-turn opening was assumed to be in the major street and $100 \mathrm{~m}$ apart from the intersection center. The simulated average delay using the VISSIM microscopic simulation model was used as the sole measure of effectiveness in this analysis.

The results shows that for low traffic volumes (i.e., total demand $\leq 3500 \mathrm{vph}$ ), the performance of the unconventional MUT design outperform the pre-timed signalized 
intersection. For heavy traffic demands, the unconventional MUT intersection design failed completely, as no vehicles were able to complete its trip through the intersection and all vehicles had to queue outside the traffic network. Furthermore, the left-turn traffic volume significantly affect the performance of the unconventional MUT design. For this it is not recommended to use this kind of design when the left-turn traffic volumes are high. Moreover, it is not recommended to use the unconventional MUT intersection design when the intersection traffic demand are higher than $3500 \mathrm{vph}$.

The results in this paper were obtained based on the assumption that passenger cars (i.e., small cars) represent $100 \%$ of the traffic composition with no pedestrians were allowed to cross the intersection. It is expected that pedestrians and trucks will affect the results obtained in this analysis and will negatively affect the performance of the unconventional MUT design even for the low traffic volumes. It is also recommended to study the effect of the length of the weaving segment on the performance of the MUT.

\section{REFERENCES}

[1] Archer, J., Indicators for traffic safety assessment and prediction and their application in micro-simulation modelling: A study of urban and suburban intersections. $\mathrm{PhD}$ thesis, Royal Institute of Technology, Kungliga Tekniska Högskolan (KTH),SE-100 44 Stockholm, Sweden, 2005.

[2] Autey, J., Sayed, T., \& El Esawey, M. (2010). Guidelines for the use of some unconventional intersection designs. In 4th International Symposium on Highway Geometric Design, Valencia, Spain.

Online $\underline{\text { http://4ishgd.webs.upv.es/index_archivo }}$ s/21.pdf (Accessed May 2015)

[3] Cunto, F., F. F. Saccomanno. Calibration and validation of simulated vehicle safety performance at signalized intersections. In Accident Analysis and Prevention. Vol. 40, 2008, pp 11711179.

[4] Duong, D., Saccomanno, F., and B. Hellinga (2010). Calibration of microscopic traffic model for simulating safety performance. Proceedings of the Annual Transportation Research Board Conference, Washington, D.C., Paper \# 10-0858

[5] El Esawey, M., \& Sayed, T. (2011). Operational performance analysis of the unconventional median U-turn intersection design. Canadian Journal of Civil Engineering, 38(11), 1249-1261.

[6] FHWA (2004). Signalized Intersection: Informational Guide. FHWA-HRT-04091. Online at: http://www.fhwa.dot.gov/publications/re search/safety/04091/04091.pdf

(Accessed May 2015)

[7] Gettman, D., and L. Head. (2003) Surrogate safety measures from traffic simulation models. In Transportation Research Record: Journal of the Transportation Research Board, No. 1840. Transportation Research Board of the National Academies, Washington D.C., 2003, pp. 104-115.

[8] Shahdah, U., Saccomanno, F., \& Persaud, B. (2014). Integrated traffic conflict model for estimating crash modification factors. Accident Analysis \& Prevention, 71, 228-235.

[9] Trafficware (2015). Synchro studio website. http://www.trafficware.com/ (accessed 2015)

[10] VISSIM 5.40 User Manual. Planung Transport Verkehr AG, Stumpfstraße 1, D-76131 Karlsruhe, Germany, 2012. 